\title{
Measure Spatial Effects of Regional Economy Based on Spatial Shift-Share Model
}

\author{
Xiao-Xin LI* \\ Department of Statistics, Tianjin University of Finance and Economics \\ Zhujiang Road25, Hexi District, Tianjin, China \\ lixiaoxin@tjufe.edu.cn \\ *Corresponding author
}

Keywords: Spatial effects of regional economy, Spatial Shift-Share model, Regional industrial spatial effects model.

\begin{abstract}
Reviews the improvements and spatial evolution process of shift-share models, discusses the economic meanings of shift-share models in different forms, constructs the complete framework of spatial shift-share model, and puts forward the regional industrial spatial effects model, which is used to measure spatial effects of regional economy. This paper measures the spatial effects of regional economy by using the economic data of the Yangtze River Delta Economic Circle and obtains some important conclusions.
\end{abstract}

\section{Introduction}

With the coordinated development of Beijing-Tianjin-Hebei Province rising for the national strategy, the issue on the coordinated development of regional economy once again becomes the hot topic. Whether the regional economic ties could be measured accurately is the key of making effective policy.

Spatial shift-share model is developed from original shift-share model, which is accessible and has clear economic meaning. In shift-share model, the economic growth of regional industry is divided into the nation effect, the industrial structure effect and the competition effect from dynamic perspective, which will help to disclose problems of industrial structure in economic growth and to provide the basis for the adjustment of industrial structure policy. By introducing the spatial elements into shift-share model, this paper makes research on regional industrial structure by considering regional economic spatial effect, which extends the research category of original shift-share model.

This paper puts forward regional industrial spatial effects model based on spatial shift-share model and applies shift-share model to measure spatial effects of regional economy, which extends the application field of the shift-share model and improves the technology tool of measuring the inter regional economic ties. The theoretical value of regional industrial spatial effects model is that the space matrix of economic geography is introduced to regional economics. Regional industrial spatial effects model with different research paradigms from traditional regional economics brings new thoughts for research and the empirical analysis of regional economics.

\section{The Spatial Evolution of Shift-Share Model}

According as the former research achievements, Dunn (1960) puts forward that the research purpose of shift-share model is to study the regional economic structure. This paper provides a review of the evolution of shift-share model.

\section{Original Shift-Share Model}

On the research of regional economic structure, shift-share model assumes that economic variables of all regions are independent spatially. The form of shift-share is:

$$
\Delta X_{i j}=X_{i j} r+X_{i j}\left(r_{i}-\mathrm{r}\right)+X_{i j}\left(r_{i j}-r_{i}\right)
$$


Where, $\Delta X_{i j}$ is the output growth of $\mathrm{i}$ industry in $\mathrm{j}$ area, $X_{i j}$ is the output of $\mathrm{i}$ industry in $\mathrm{j}$ area, ris the growth rate of all industries in all regions, $r_{i}$ is the growth rate of $i$ industry in all regions, $r_{i j}$ is the growth rate of $i$ industry in $j$ area.

The meaning of this model is that output growth of $\mathrm{i}$ industry in $\mathrm{j}$ area is divided into three parts: the first item $X_{i j} r$ is the national effect, which is the output growth of $\mathrm{i}$ industry at the growth rate of all industries in all regions; $X_{i j}\left(r_{i}-r\right)$ is the structural effect which means the excess growth due to industry advantage of $i$ industry at the growth rate beyond the growth rate of all industries in all areas; $X_{i j}\left(r_{i j}-r_{i}\right)$ is the competitive effect, which means the excess growth due to competition advantage of $\mathrm{i}$ industry in $\mathrm{j}$ area at the growth rate beyond the growth rate of $\mathrm{i}$ industry in all areas.

\section{The Improvement of Shift-Share Model}

In the model (1), the flaw of the competitive effect $X_{i j}\left(r_{i j}-r_{i}\right)$ is that different areas with the same base-period output and growth rate may have different output growth due to the different industrial structures. In other words, $X_{i j}$ have different distributions. To solve this problem, Marquillas (1972) introduces homothety $X_{i j}{ }^{*}$ and assumes that the based-period industrial structure in $\mathrm{j}$ area is as the same as the national industrial structure. The improved shift-share model is:

$$
\Delta X_{i j}=X_{i j} r+X_{i j}\left(r_{i}-r\right)+X_{i j}^{*}\left(r_{i}-r\right)+\left(X_{i j}-X_{i j}^{*}\right)\left(r_{i j}-r_{i}\right)
$$

Where, $X_{i j}^{*}=\sum_{\mathrm{i}=1}^{\mathrm{s}} X_{i j} \frac{\sum_{j=1}^{R} X_{i j}}{\sum_{i=1}^{S} \sum_{j=1}^{R} X_{i j}}=\frac{\sum_{\mathrm{j}=1}^{\mathrm{s}} \mathrm{X}_{\mathrm{ij}}}{\sum_{\mathrm{i}=1}^{\mathrm{s}} \sum_{\mathrm{j}=1}^{\mathrm{R}} \mathrm{X}_{\mathrm{ij}}} \sum_{j=1}^{R} X_{i j}$

The first two items of model (2) are as the same as the model (1); the third item of the new model is the net competitive effect, which means the competitive effect without the influence of regional industrial structure; the forth item is locational effect which is the reflection of the specialization level of a region.

\section{Spatial Shift-Share Model}

With the deepening of economic analysis, the assumption of regional spatial independence is unrealistic. Economist goes in for the improvement of the shift-share model, and then the spatial shift-share model comes out. Anselin(1988) introduces spatial to improve shift-share model.The spatial weight matrix is defined as $W=\left[\begin{array}{cccc}0 & w_{12} & \cdots & w_{1 R} \\ w_{21} & 0 & w_{2 R} \\ \vdots & & \vdots \\ w_{R 1} & w_{R 2} & \cdots & 0\end{array}\right]$, Where, $w_{j k}$ is the interaction between $\mathrm{j}$ area and $\mathrm{i}$ area.

Furthermore, the calculation of $w_{j k}$ is the key to spatial weight matrix. At present, there are two ways to calculate spatial element $w_{j k}$. One way is to use the geographic distance, which means that everything is related to each other, but the correlation decreases with the increase of distance. Another way to calculate spatial element $w_{j k}$ is to use economic distance.

\section{The Calculation of Economic Spatial Weight Matrix}

There are some ways to calculate the economic spatial weight matrix.

Case (1993)defines $w_{j k}=1 /\left|x_{j}-x_{k}\right|$, where, $x_{j}$ and $x_{k}$ are the per capita incomes or alternative economic variables of $\mathrm{j}$ area and $\mathrm{k}$ area. The smaller gap of the per capita income between two regions, the larger value of $w_{j k}$.If the two regions have the same per capita income, the value of $w_{j k}$ tends to be infinity.

Molho(1995) defines $\boldsymbol{w}_{\boldsymbol{j} \boldsymbol{k}}=\frac{\boldsymbol{E}_{\boldsymbol{j}} \boldsymbol{e}^{\left(-\boldsymbol{\eta} \boldsymbol{d}_{j \boldsymbol{k}}\right)}}{\sum_{\boldsymbol{l} \neq j} \boldsymbol{E}_{\boldsymbol{l}} \boldsymbol{e}^{\left(-\boldsymbol{\eta} \boldsymbol{d}_{\boldsymbol{j} l)}\right.}}$, where, $\boldsymbol{E}_{\boldsymbol{j}}$ and $\boldsymbol{E}_{\boldsymbol{l}}$ are the quantities of employment of $\mathrm{j}$ area and $\mathrm{l}$ area, $\boldsymbol{\eta}$ is the exponential smoothing. The quantity of employment is introduced into the formula, which is adjusted by geographical distance $\frac{1}{\sum_{l \neq j} E_{l} e^{\left(-\eta d_{j l}\right)}}$. The key of thismethod is how to determine the value of exponential smoothing $\eta$. 
Boarnet(1998) puts forward the formulaw $w_{j k}=\frac{1 /\left|x_{j}-x_{k}\right|}{\sum_{k} 1 /\left|x_{j}-x_{k}\right|}$, which has the same variable setting method as the formula Case defines in 1993 and adjusts Case's formula by $\frac{\mathbf{1}}{\sum_{k} \mathbf{1} /\left|\boldsymbol{x}_{j}-\boldsymbol{x}_{\boldsymbol{k}}\right|}$.

Fingleton(2001) puts forward the formula $w_{j k}=G D P_{t=0}^{2} d_{j k}^{-2}$, where, $G D P_{t=0}$ is the base period GDP of $\mathrm{j}$ area, $d_{j k}$ is the geographical distance between $\mathrm{j}$ area and $\mathrm{k}$ area. Economic distance is the region's GDP which is adjusted by the geographical distance $d_{j k}$

\section{The Regional Industrial Spatial Effects Model based on Spatial Shift-Share Model}

This paper introduces the spatial weight matrix into the shift-share model, definite a new variable $X_{i j}^{v *}=\sum_{k \in V} w_{j k} X_{i k}$ and introduces it into the shift-share model:

$$
\Delta X_{i j}=X_{i j} r+X_{i j}\left(r_{i}-\mathrm{r}\right)+X_{i j}{ }^{*}\left(r_{i j}-r_{i}\right)+\left(X_{i j}-X_{i j}^{v *}\right)\left(r_{i j}-r_{i}\right)
$$

Model (3) is spatial shift-share model, andthe meanings of the first two items are as the same as model (1); the meaning of the third item is the net effect of spatial competition, which reflects the direct effect of the industries in surrounding areas on a industrial growth in a area; the meaning of the fourth item is location effect, which reflects the gap of a industry between a area and surrounding areas.

One problem of spatial shift-share model is $\sum_{i j} X_{i j}^{v *} \neq \sum_{i j} X_{i j}$. To solve this problem, asubstitute variable $X_{i j}^{v^{* *}}$ is involved, which is based on the new regional spatial weight. The weight depends on $X_{i j}^{v *}$, that is $\mathrm{X}_{\mathrm{ij}}^{\mathrm{v}^{* *}}=\mathrm{X}_{\mathrm{j}} \frac{\mathrm{X}_{\mathrm{i}}^{\mathrm{v}^{*}}}{\mathrm{X}^{\mathrm{v}^{*}}}$, where, $\frac{\sum_{\mathrm{j}=1}^{\mathrm{R}} \mathrm{X}_{\mathrm{ij}}^{\mathrm{v}^{*}}}{\sum_{\mathrm{i}=1}^{\mathrm{s}} \sum_{\mathrm{j}=1}^{\mathrm{R}} \mathrm{X}_{\mathrm{ij}}^{\mathrm{v}^{*}}}=\frac{\mathrm{X}_{\mathrm{i}}^{\mathrm{v}^{*}}}{\mathrm{X}^{\mathrm{v}^{*}}}$, and $\mathrm{X}_{\mathrm{ij}}^{\mathrm{v}^{* *}}$ makes $\sum_{i j} X_{i j}^{v * *}=$ $\sum_{i j} X_{i j}$.The economic implication of this change is that $\mathrm{j}$ area has the same industrial spatial structure as the surrounding areas.

The improved spatial shift-share model is:

$$
\Delta X_{i j}=X_{i j} r+X_{i j}\left(r_{i}-r\right)+X_{i j}^{v^{* *}}\left(r_{i j}-r_{i}\right)+\left(X_{i j}-X_{i j}^{v^{* *}}\right)\left(r_{i j}-r_{i}\right)
$$

Basing on the improved spatial shift-share model, we can define $X_{i j}^{v^{* *}}\left(r_{i j}-r_{i}\right)$ as regional industrial spatial effects model:

$$
X_{i j}^{*}=X_{i j}^{v^{* *}}\left(r_{i j}-r_{i}\right)
$$

Where, $X_{i j}^{*}$ is the influence of regional space on i industry in $\mathrm{j}$ area, other variables in this model have the same meaning as the variables in model (4).

Regional industrial spatial effects model is used to measure the economic effects of the industries in surrounding areas on the local industries. Compared with other measurements, this model has strong operability and could provide more economic information. Furthermore, if $\mathrm{i}$ industry of $\mathrm{j}$ area has the regional competitive advantage, regional spatial effect is positive, which means that $\mathrm{i}$ industry of $\mathrm{j}$ area will benefit from the development of regional economic; and vice versa. The value of regional spatial effect is determined by regional spatial production and competitive edge. This model is not only used to study the nationwide industrial spatial effects, but also used to study the regional industrial spatial effects.

\section{Regional Industrial Spatial Effects on the Yangtze River Delta Economic Circle}

This paper chooses Jiangsu Province which is one of provinces in the Yangtze River Delta as a target area, takes Shanghai, Zhejiang Province and Anhui Province as the surrounding areas and analyzes the effects of the manufacturing industries in these three provinces on Jiangsu Province during 2014-2015 by regional industrial spatial effects model. 17 manufacturing industries are determined for calculation according to the national industrial classification directory. 
The imbalance of regional economy in China leads to urban per capita disposable income gap in different regions, so urban per capita disposable income reflects the regional economic development and people's living level. This paper takes urban per capita disposable incomeas the economic variables, and calculates the spatial weight matrix by Boarnet's method. The Spatial weight values of Jiangsu Province, Zhejiang Province, Anhui Province are 0.2265, 0.4838, 0.2897, which shows that urban per capita disposable income in Jiangsu Province is closed to the situation in Zhejiang Province.

This paper calculates the spatial economic effects values of 17 manufacturing industries by regional industrial spatial effects model. The results are shown in table 1 and table 2.

Table 1 Calculating table of regional industrial spatial effects model

\begin{tabular}{|c|c|c|c|c|c|c|}
\hline \multirow[b]{2}{*}{ Industry } & \multicolumn{4}{|c|}{$X_{i j}^{v *}($ Billion yuan $)$} & \multirow{2}{*}{$\begin{array}{c}X_{i j}^{v^{* *}} \\
\text { (Billion yuan) }\end{array}$} & \multirow[b]{2}{*}{$r_{i j}-r_{i}$} \\
\hline & Jiangsu & $\begin{array}{l}\text { Shangha } \\
\text { i }\end{array}$ & Zhejiang & Anhui & & \\
\hline Food & 427.36 & 440.39 & 465.21 & 474.06 & 282.99 & -0.0153 \\
\hline Beverage & 383.42 & 534.96 & 483.47 & 547.94 & 305.34 & 0.0428 \\
\hline Textile & 3087.25 & 5040.09 & 2967.35 & 4781.33 & 2486.24 & -0.0206 \\
\hline Papermaking & 679.35 & 1001.7 & 685.11 & 979.42 & 523.93 & -0.0193 \\
\hline $\begin{array}{l}\text { Petroleum } \\
\text { processing }\end{array}$ & 1343.76 & 1578.48 & 1546.97 & 1799.44 & 981.69 & 0.0051 \\
\hline Chemical & 3221.31 & 6148.09 & 6450.13 & 7601.00 & 3667.73 & 0.0159 \\
\hline Pharmaceutical & 615.32 & 1048.22 & 1036.55 & 1229.96 & 615.46 & 0.0590 \\
\hline Chemical fiber & 1284.09 & 2085.22 & 1035.95 & 1891.26 & 986.06 & -0.0201 \\
\hline Nonmetal ore & 1402.73 & 2127.46 & 1850.04 & 2184.95 & 1184.73 & -0.0438 \\
\hline Black metal & 2021.83 & 3955.64 & 4706.97 & 5118.70 & 2474.82 & 0.0002 \\
\hline Nonferrous metal & 1568.45 & 2252.56 & 1781.05 & 2177.41 & 1218.29 & -0.0934 \\
\hline Metal ware & 1427.27 & 2371.92 & 2175.94 & 2683.16 & 1355.92 & -0.0113 \\
\hline Specialized facility & 1135.78 & 1984.54 & 2353.99 & 2571.91 & 1260.06 & 0.0263 \\
\hline Transportation & 3631.45 & 4683.37 & 5706.33 & 5940.73 & 3126.10 & 0.0382 \\
\hline $\begin{array}{l}\text { Electrical and } \\
\text { machinery }\end{array}$ & 3855.11 & 6677.97 & 6527.71 & 7650.16 & 3869.82 & 0.0667 \\
\hline Communication & 2603.93 & 5606.73 & 9064.66 & 9154.00 & 4138.92 & 0.0317 \\
\hline Instrument & 468.56 & 1130.46 & 1249.70 & 1486.34 & 678.88 & 0.1625 \\
\hline
\end{tabular}

Table 2 Regional spatial effects on 17 manufacturing industries

\begin{tabular}{|l|l|l|l|}
\hline Industries & Effects & Industries & Effects \\
\hline Food & -4.33 & Black metal & 0.49 \\
\hline Beverage & 13.07 & Nonferrous metal & -113.79 \\
\hline Textile & -51.22 & Metal ware & -15.32 \\
\hline Paper-making & -10.11 & Transportation & 119.42 \\
\hline $\begin{array}{l}\text { Petroleum } \\
\text { processing }\end{array}$ & 5.01 & Specialized facility & 33.14 \\
\hline Nonmetal ore & -51.89 & Electrical and machinery & 258.12 \\
\hline Pharmaceutical & 36.31 & Communication & 131.20 \\
\cline { 1 - 2 } Chemical fiber & -19.82 & Instrument & 110.32 \\
\cline { 1 - 2 } Chemical & 58.32 & & \\
\cline { 1 - 3 } & & &
\end{tabular}


The highest surrounding spatial values of 17 manufacturing industries in Jiangsu Province are communication, electrical and machinery, chemical, transportation and textile industries, while the highest output values of 17 manufacturing industries in Jiangsu Province are communication, chemical, electrical and machinery, black metal and transportation industries. By comparison, there are four industries with highest surrounding spatial values are the industries with the highest output values in Jiangsu Province, which means that these four industries in the Yangtze River Delta economic circle has formed spatial industrial agglomeration effect. The lowest surrounding spatial values of 17 manufacturing industries in Jiangsu Province are food, beverage, papermaking, and pharmaceutical industries, which are industries with lowest output values in Jiangsu Province. The industrial patterns of Jiangsu Province and the Yangtze River Delta economic circle are harmonious.

Jiangsu province has competitive advantages in 10 industries such as instrument, electrical and machinery, pharmaceutical, beverage and transportation industries, and the growth rates of them are higher than the average growth rates of the same industries in the Yangtze River Delta economic circle. Compared with the same industries in the Yangtze River Delta economic circle, food, textile, papermaking, chemical fiber, nonmetal ore, and nonferrous metal and metal ware industries in Jiangsu Province don't have comparative advantages. Instrument, pharmaceutical and beverage industries with low output values in Jiangsu Province have comparative advantages compared with the same industries in the Yangtze River Delta economic circle. So those three industries should be developed to make regional industries diversified and complementary.

It is shown in table 2 the spatial effect outputs in Jiangsu Province compared with three surrounding provinces, which means that the industries of the surrounding provinces affects growth rate of the same industries in Jiangsu Province by competitive advantage of the industries in Jiangsu Province. In other words, if an industry of Jiangsu Province has competitive advantage, it could absorb achievements of the industry in surrounding provinces; if an industry of Jiangsu Province does not have competitive advantage, its achievements could be absorbed by the industry in surrounding provinces. The highest surrounding spatial values of 17 manufacturing industries in Jiangsu Province are electrical and machinery, communication, transportation, instrument and chemical industries. Except instrument industry, the rest four industries are the industries with highest output values, which means these four industries benefit the most from the industrial agglomeration.

\section{Summary}

On the base of existing spatial shift-share model, this paper puts forward a new method to measure spatial effects of regional economy: regional industrial spatial effects model, which overcomes the shortcomings of the existing methods, and has the following advantages: the data is more accessible and the calculation process is more simple and clear. This paper makes the empirical analysis on the manufacturing industries in the Yangtze River Delta economic circle, the calculation results of which could provide a theoretical basis for the policy-making of the regional coordinated development, re planning and layout of industries.

\section{Acknowledgement}

This research is financially supported by the National Bureau of Statistics of People's Republic of China(Project Number: 2014LD03).

\section{References}

[1]Dunn, E.S. A statistical and analytical technique for regional analysis. Papersof the Regional Science Association(1960) 97-112.

[2]Anselin. L, Spatial econometrics methods and models. Ed. KluwerAcademicPublishers, 1988. 
[3]Moran, P, The interpretation of statistical maps. Journal of the RoyalStatistical Society (1948)243-251.

[4]Molho, I, Spatial autocorrelation in British unemployment. Journal ofRegional Science (1955)641-658.

[5]Boarnet, M.G, Spillovers and the Locational Effects of Public Infrastructure. Journal of Regional Science (1998)381-400.

[6]Fingleton, B, Equilibrium and Economic Growth: Spatial Econometric Modelsand Simulations. Journal of Regional Science (2001)117-147.

[7]Mayor M, Lopez AJ, The Spatial Shift-Share Analysis New Developments and Some Findings for the Spanish Case. In $45^{\text {th }}$ Congress of the European Regional Science Association, 2005. 